\title{
Lipoma arborescens-a rare cause of monoarticular knee joint swelling in adolescents-case report
}

\begin{abstract}
Lipoma Arborescens is a slowly progressive intraarticular lesion of knee characterised by substitution of sub synovial tissue with fat cells and villous transformation of synovium. It is a rare entity with limited literature. We present a case of lipoma arborescens in 17 year old boy who presented with complaints of mono-articular swelling of left knee for 2 years with history of antecedent trauma. MRI showed frond like masses present in supra and infrapatellar region with high signal intensity on $\mathrm{T} 1 \mathrm{~W}$ and Intermediate signal intensity on $\mathrm{T} 2 \mathrm{~W}$, consistent with fat. He was managed with open synovectomy which showed yellowish white polypoidal and villous masses of adipose tissue. Masses were sent for histopatholgy which showed hypertrophic villous projections of fat lined by synovial cells. Patient became asymptomatic postoperatively and improved functionally.
\end{abstract}

Keywords: Lipoma Arborescens, open synovectomy, mono-articular knee swelling
Volume II Issue 3 - 2019

\author{
Vibhav Gandhi,' Shagun Shory, ${ }^{3}$ Avinash \\ Kumar, ${ }^{4}$ Mohit Jindal, ${ }^{2}$ Mohit Goyal, ${ }^{2}$ Nipun \\ Aggarwal, ${ }^{2}$ Vipul Shory, ${ }^{5}$ Ayushi Bansal ${ }^{6}$ \\ 'Department of Orthopaedics, Punjab Institute of Medical \\ Sciences, India \\ 2Department of Orthopaedics, Kalpana Chawla Government \\ Medical College, India \\ ${ }^{3}$ Department of Anaesthesiology, S.B.K.S. Medical Institute and \\ Research Centre, India \\ ${ }^{4}$ Department of Orthopaedics, Mata Gujri Memorial College, \\ India \\ ${ }^{5}$ Department of General Surgery, S.B.K.S. Medical Institute and \\ Research Centre, India \\ ${ }^{6}$ Department of Pathology, Kalpana Chawla Government \\ Medical College, India
}

Correspondence: Vibhav Gandhi, Senior Resident, Department of Orthopaedics, Kalpana Chawla Government Medical College, Karnal, Haryana, India, Email drmohitjindalortho@gmail.com

Received: April 22, 2019 | Published: May 20, 2019

\section{Introduction}

Lipoma Arborescens is a rare articular lesion consisting of subsynovial villous proliferation of mature fat cells. ${ }^{1}$ The knee joint is the most commonly involved joint. ${ }^{2}$ The term arborescens in latin means "tree like" which describes the characteristic villous and frond like morphology of this condition. ${ }^{3}$ The term lipoma is misleading as it does not show any features of a neoplasm The condition is rare with unclear aetiology. It is usually found in 9-68 years of age. It is extremely rare in children. It is most commonly mono-articular but can present as poly-articular or bilateral involvement. ${ }^{3}$ Although suprapatellar pouch of knee joint is commonly involved, it has been reported in shoulder, hip, elbow and wrist. There have been reports of involvement of subdeltoid and bicipital bursa and the synovial sheath of peroneal tendons. ${ }^{4-6}$ MRI is the imaging modality of choice. ${ }^{3}$ Characteristic MRI feature of lipoma arborescence is high signal intensity villous mass on T1 and T2 weighted sequence with signal intensity similar to fat. The recommended treatment is open or arthroscopic synovectomy. The recurrences are uncommon.

\section{Case report}

17 year old boy presented with history of swelling in the left knee for 2 years which was initially painless now painful. Patient had history of trauma 2 years back following which he was investigated in tertiary care institute and found to have no bony injury. He was managed with a cylindrical slab for 2 months. Following the removal of slab patient remained asymptomatic for 1 month then developed swelling of the knee. Patient was evaluated for causes of monoarticular knee swelling, RA factor was negative, Uric acid was within normal limits, ESR was 54. Synovial fluid analysis was done which showed no crystals and pus cells. Patient was managed conservatively for few months on anti-inflammatory drugs and rest. Knee swelling did not resolve and patient was subjected to MRI of knee which showed frond like mass present in supra and infrapatellar region which had high signal intensity on $\mathrm{T} 1$ weighted images and intermediate signal intensity on T2 weighted images which was consistent with adipose tissue. Moderate joint effusion was observed and no ligamentous injury was seen. Patient was advised surgery but failed to follow up. Now he presented to us with mono-articular knee swelling. On examination moderate effusion of knee joint was present with doughy feeling in supra patellar pouch. Knee was grossly tender. Range of movements of left knee was restricted with 0 - 110 degree flexion. Lymphadenopathy was absent. Opposite knee and other joints were normal. Repeat ESR was 40. Xrays showed no gross abnormality. He was taken up for arthrotomy of left knee with synovectomy and excision of mass. Intraoperatively it was observed that there was synovial hypertrophy with yellowish white masses in supra and infrapatellar region. Masses were excised and sent for biopsy. On histopathology hypertrophic villous projections were seen which were lined by synovial cells with variably scattered inflammatory cells, predominantly lymphocytes and plasma cells. Patient was followed regularly in post-operative period at 1 week, 2 weeks, 4 weeks and 12 weeks post- surgery. Patient returned to his routine activities and had good functional outcome (Figure 1-6). 


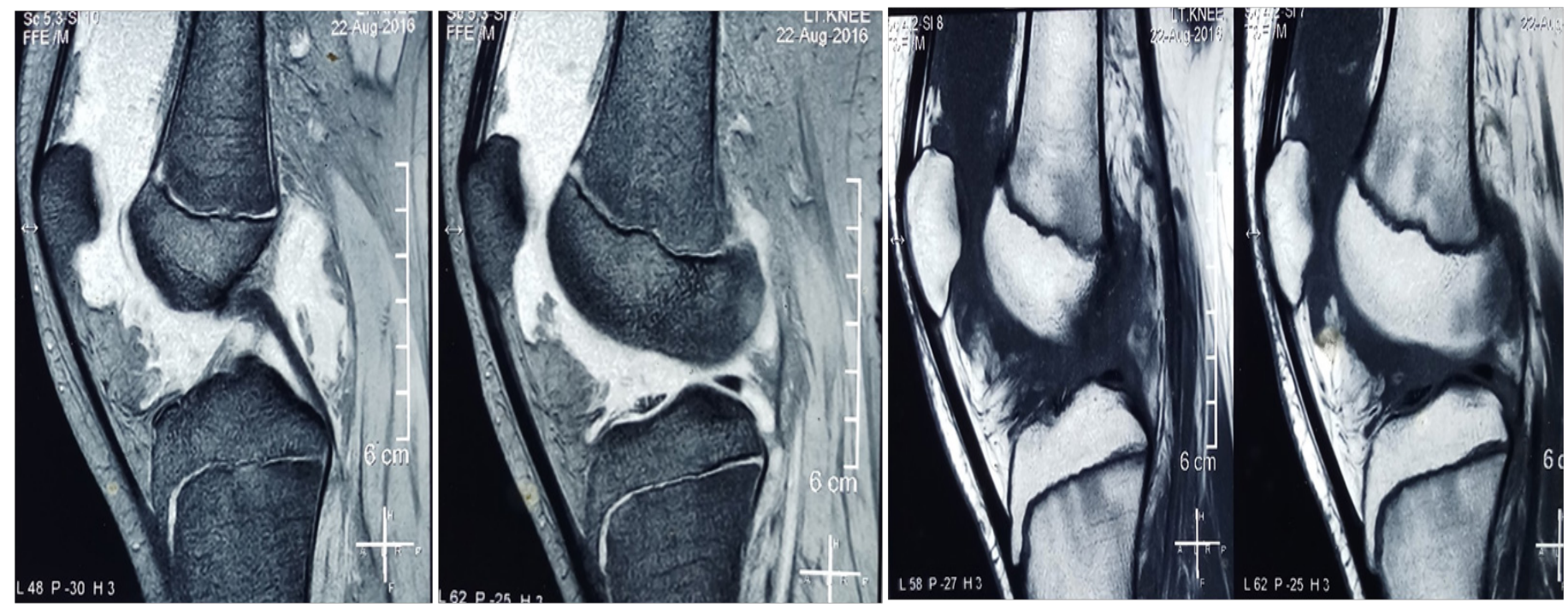

Figure Ia \& Ib T2 and TI weighted MRI images of the knee joint of patient depicting villous fatty tissue growth in infrapatellar region.

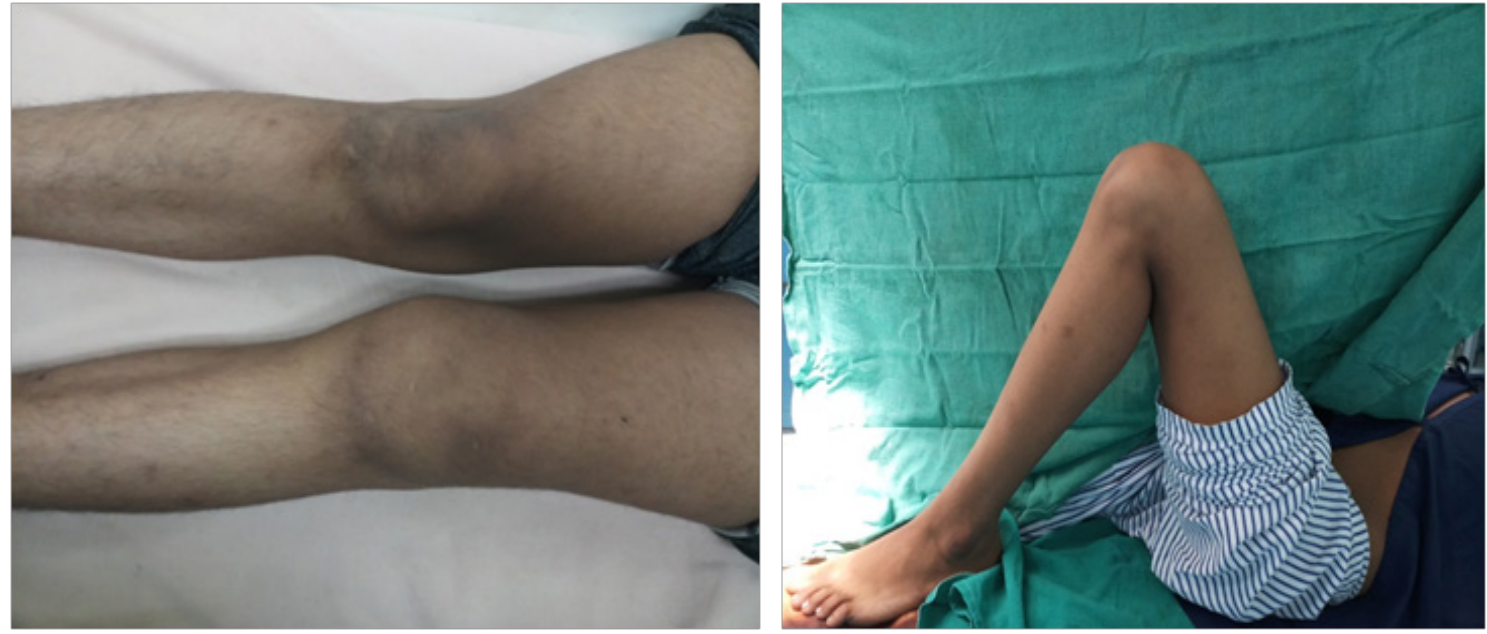

Figure $2 \mathbf{a}$ \&b Clinical pictures of left knee of the patient demonstrating swelling of left knee and decreased range of motion.
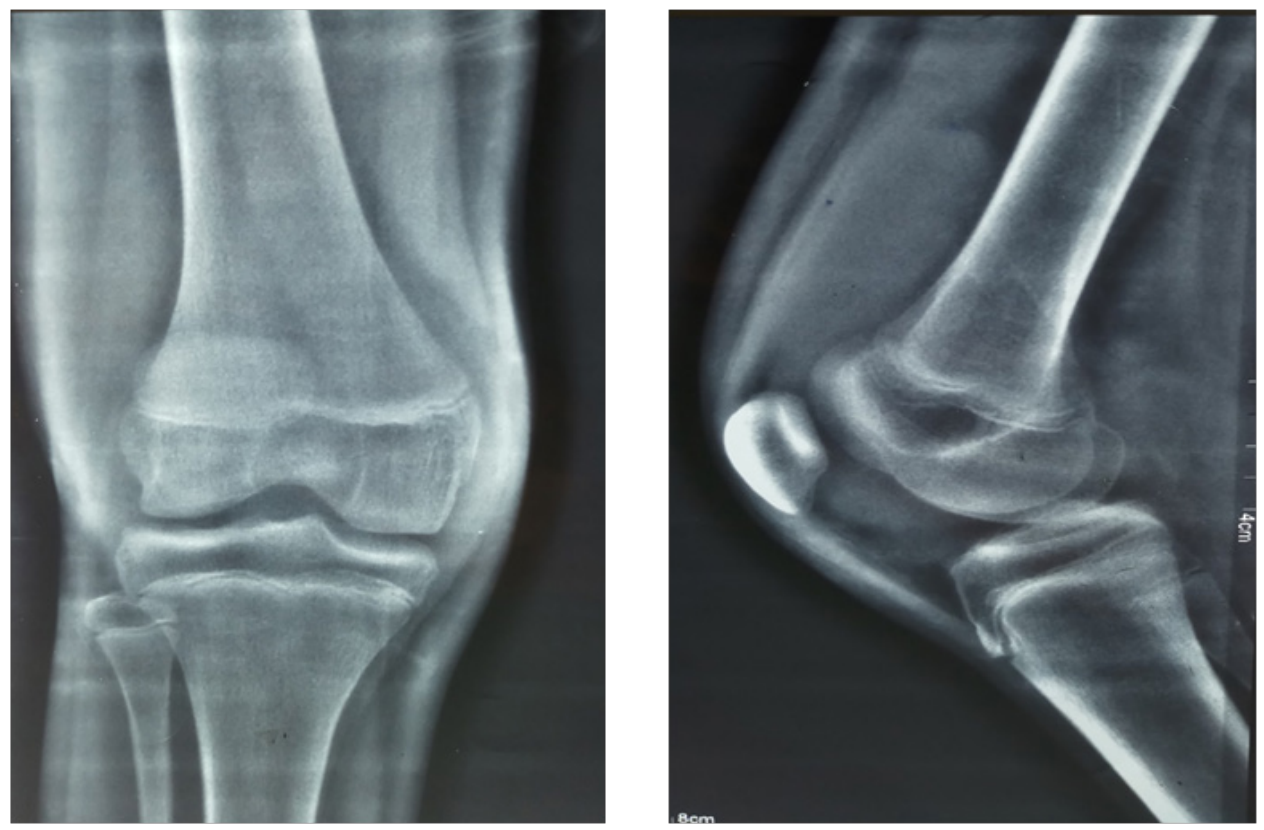

Figure 3 Plain radiographic images of left knee joint, antero-posterior and lateral views.

Citation: Gandhi V, Shory S, Kumar A, et al. Lipoma arborescens-a rare cause of monoarticular knee joint swelling in adolescents-case report. MOJ Orthop Rheumatol. 2019; I (3): I20-123. DOI: I0.15406/mojor.2019.1 I.00484 

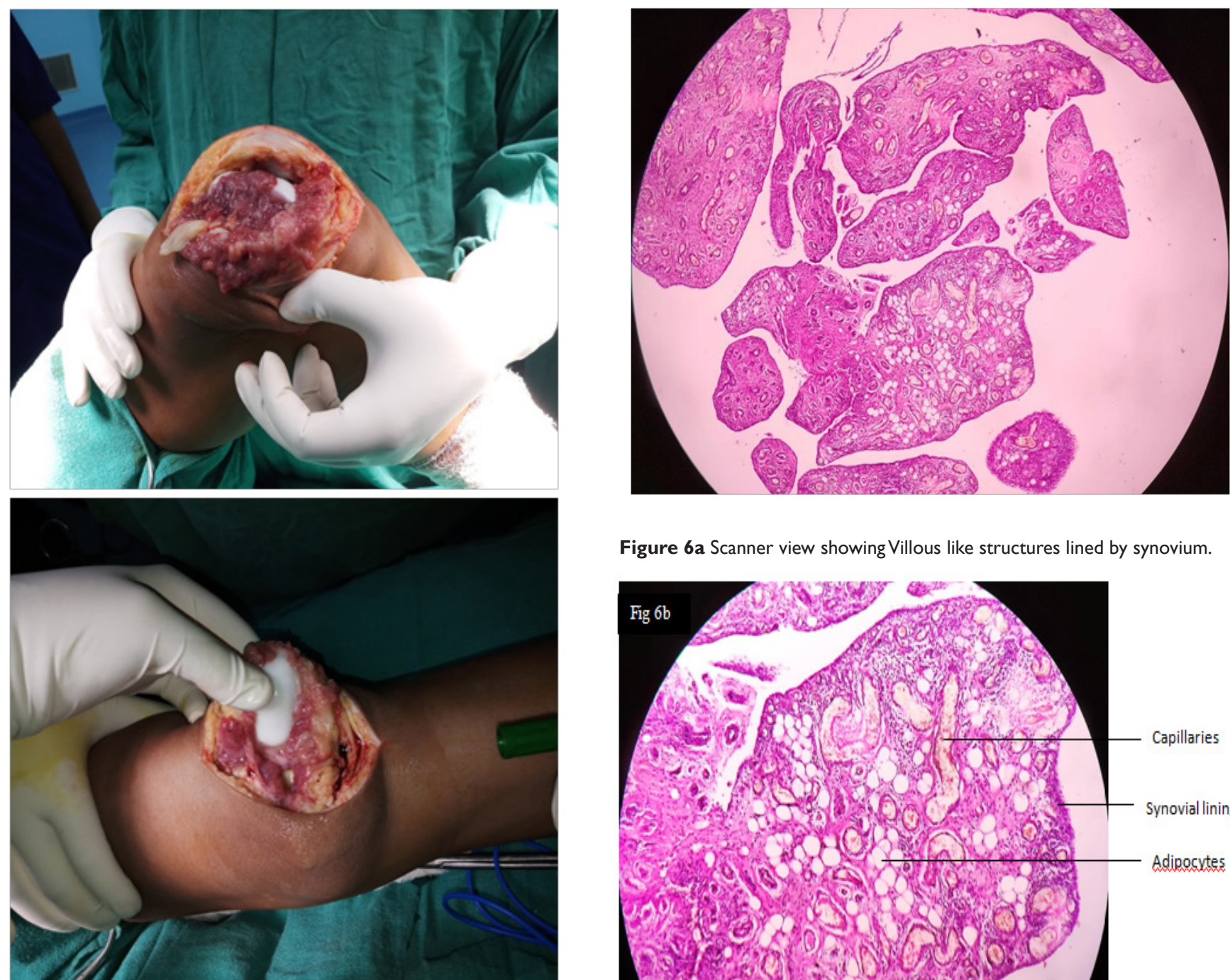

Figure 4 Intraoperative pictures showing synovial hypertrophy and yellowish white mass in the suprapatellar region of left knee joint.

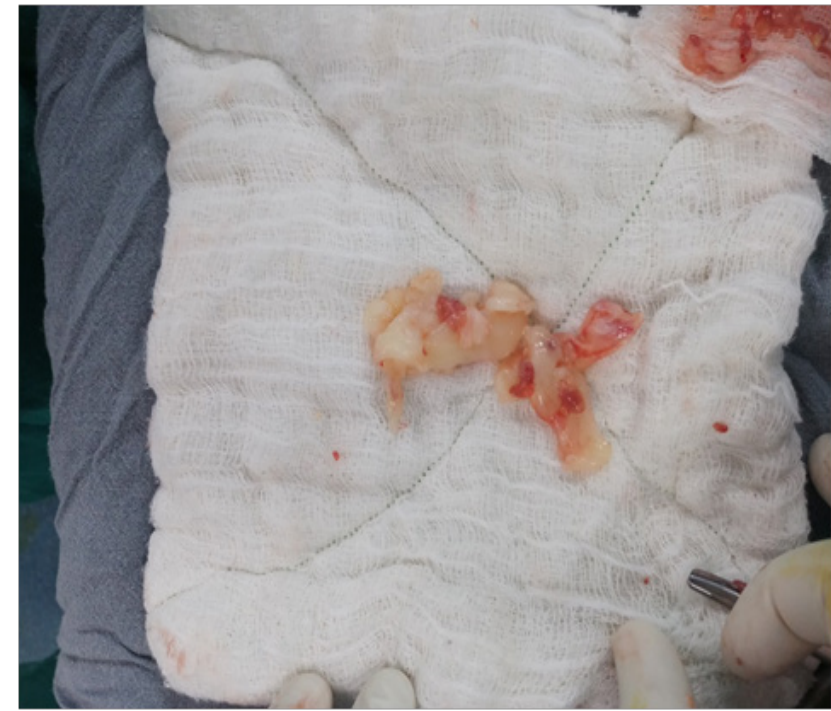

Figure 5 Gross appearance of Lipoma Arborescens- appears as yellowish white polypoidal mass.
Figure 6a Scanner view showing Villous like structures lined by synovium.
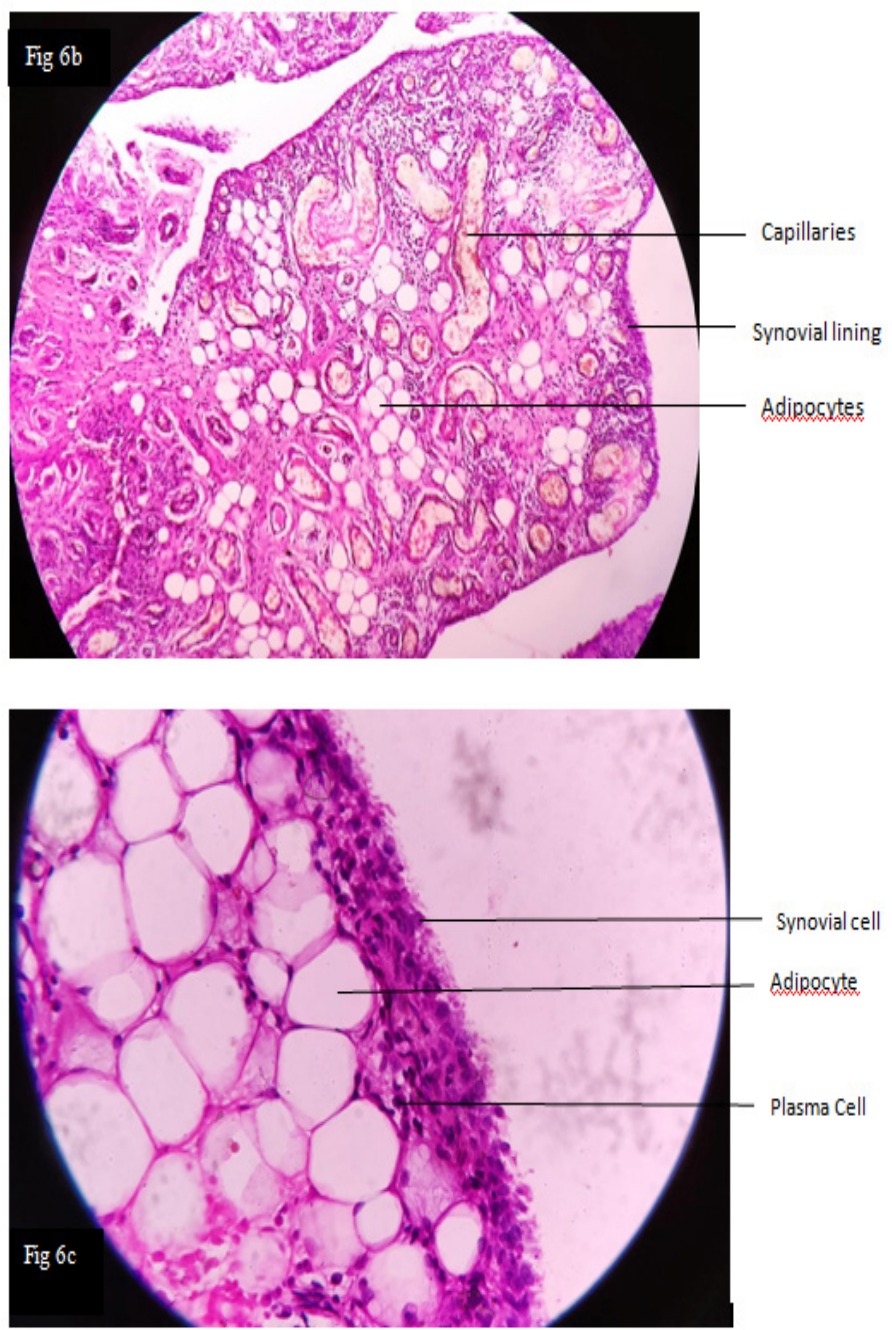

Figure 6b \& c 10x and 40x magnification showing-villous structures are lined by synovial cells and contain within them proliferating thin walled capillaries and benign adipocytes along with dense, diffuse plasmacytic infiltrate. 


\section{Discussion}

Lipoma arborescens (LA) is a rare intra-articular lesion characterised by diffuse replacement of subsynovial tissue with mature adipocytes and villous proliferation of overlying synovium. It was first described by German surgeon, Albert Hoffa in 1904 and was later described in detail by Arzimanoglu in 1957. ${ }^{7,8}$ It most commonly affects knee but lesions in other articular sites like hip, ankle, wrist, elbow and shoulder; as well as extra articular sites like synovial sheath and bursae. Peak incidence is between 30-50 years but it has been observed between 9 to 68 years of age. No sex preponderance has been observed. ${ }^{3}$ Its aetiology is unknown but it has been associated with trauma, degenerative conditions or inflammatory joint diseases. There are two aetiological types of lipoma arborescens, primary and secondary, depending on age of presentation and underlying condition. ${ }^{9,10}$

Primary LA is idiopathic and occurs in younger population between ages 20 to 30 years. Secondary LA is more common and defined as synovial lipomatosis associated with chronic synovial irritation due to degenerative disease, trauma, meniscal injury and infection. ${ }^{3}$ It is generally seen in older population. Patients with lipoma arborescens can present with slow progressive swelling, intermittent episodes of joint effusion, restriction of range of motion, locking and pain. On examination the joint can appear effused with a palpable mass in the supra patellar pouch.

MRI is the imaging modality of choice for diagnosis of lipoma arborescens. Laboratory findings are nonspecific. Plain radiograph can show soft tissue periarticular soft tissue opacity, osteoarthritic features or non-specific erosion. On ultrasonography a frond like hyperechoic mass is seen that waves during manipulation of joint. CT scan although done rarely may demonstrate villous synovial mass with soft tissue density similar to fat with no enhancement on contrast. ${ }^{11}$ Lipoma Arborencens can be distinguished from other intraarticular masses with its pathognomic appearance on MRI. It appears as frond like mass with signal intensity similar to subcutaneous fat on all pulse sequences. It shows high signal intensity on T1 and T2 weighted images which get suppressed on short tau inversion recovery or fat suppression sequences. With contrast the mass does not enhance however synovial layer and joint fluid show enhancement. MRI may also demonstrate joint effusion and degenerative changes like chondropathy and osteophytes. ${ }^{11}$

Grossly it appears as yellowish white mass with frond like pattern. On histopathology there is papillary proliferation of synovial villi with substitution of subsynovial tissue by mature adipocytes. Overlying synovium contains mononuclear infiltrates and the synovial cells are enlarged with eosinophilic cytoplasm. ${ }^{12}$ Treatment of lipoma arborescens is surgical excision either open or arthroscopic. Other treatment modalities like yttrium 90 radio synovectomy and chemical synovectomy with osmic acid has also been described. ${ }^{13}$ Recurrence after excision is uncommon. ${ }^{14}$

\section{Conclusion}

Lipoma arborescens is a rare cause of intra articular mass but its possibility needs to be kept in differential diagnosis. Its characteristic appearance on MRI is pathognomic and helps in differentiating from other pathologies. Open or arthroscopic synovectomy gives satisfactory results with low incidence of recurrence.

\section{References}

1. Hallel T, Lew S, Bansal M. Villous lipomatous proliferation of the synovial membrane (lipoma arborescens). J Bone Joint Surg Am. 1988;70(2):264-270.

2. Yan CH, Wong JWK, Yip DKH. Bilateral knee lipoma arborescens: a case report. J Orthop Surg Hong Kong. 2008;16(1):107-110.

3. Sanamandra SK, Ong KO. Lipoma arborescens. Singapore Med J. 2014;55(1):5-11.

4. Senocak E, Gurel K, Gurel S, et al. Lipoma arborescens of the suprapatellar bursa and extensor digitorum longus tendon sheath: report of 2 cases. $J$ Ultrasound Med. 2007;26(10):1427-1433.

5. Laorr A, Peterfy CG, Tirman PF, et al. Lipoma arborescens of the shoulder: magnetic resonance imaging findings. Can Assoc Radiol J. 1995;46:311-313.

6. Dawson JS, Dowling F, Preston BJ, et al. Case report: lipoma arborescens of the sub-deltoid bursa. Br J Radiol. 1995;68(806):197-199.

7. Hoffa A. The influence of the adipose tissue with regard to the pathology of the knee joint. JAMA. 1904;43(12):795-796.

8. Arzimanoglu A. Bilateral arborescent lipoma of the knee. J Bone Joint Surg Am. 1957;39(4):976-979.

9. Vilanova JC, Barceló J, Villalón M, et al. MR imaging of lipoma arborescens and the associated lesions. Skeletal Radiol. 2003;32(9):504 509.

10. Patil PB, Kamalapur MG, Joshi SK, et al. Lipoma Arborescens of Knee Joint: Role of Imaging. J Radiol Case Rep. 2011;5(11):17-25.

11. De Vleeschhouwer M, VAN DEN STEEN E, Vanderstraeten G, et al. Lipoma Arborescens: Review of an Uncommon Cause for Swelling of the Knee. Case Rep Orthop. 2016;2016:1-5.

12. Kulkarni HG, Kulkarni GS, Kulkarni PG. Lipoma Arborescens - Eyes See What Mind Knows! J Orthop Case Rep. 2017;7(5):59-62.

13. Erselcan T, Bulut O, Bulut S, et al. Lipoma arborescens; successfully treated by yttrium-90 radiosynovectomy. Ann Nucl Med. 2003;17(7):593596.

14. Erol B, Ozyurek S, Guler F, et al. Lipoma arborescens of the knee joint. BMJ Case Rep. 2013;17(7):593-596. 